\title{
UN FENÓMENO DE REPETICIÓN TEXTUAL: EL ESTRIBILLO EN EMILIO PRADOS
}

\author{
Mario Garcia-Page \\ UNED \\ mgarcia-page@flog.uned.es
}

\begin{abstract}
Resumen
A feature of Emilio Prados's poetical production/creation is the use of the refrain, a characteristic resource of popular traditional poetry, particularly that of the in-parallel type. The refrain is not only a versification device but also a rhetorical repetition figure of a textual kind. As a repetition phenomenon it becomes apparent in Prados's poetry in different ways. Inexact repetition or repetition with variations, and, particularly, the deliberate breaking in the last occurrence at the end of the poem are representative of the two main shapes the refrain takes.
\end{abstract}

1. Gran parte de la producción lírica de Emilio Prados entronca con esa vertiente de la más rancia poesía española tradicional de corte popular que adopta el estribillo $-\mathrm{o}$ villancico- como forma poética!

Junto a esta característica, destacan en el quehacer artístico de Prados otros cuatro rasgos propios de esta corriente lírica neopopular: la organización del poema en estrofas, el verso rimado, la forma métrica (ritmo cuantitativo-silábico) y la estructura paralelística; de hecho, muchos de los poemas estribillísticos del citado autor están organizados en virtud de ciertos diseños de paralelismo y sus estrofas, compuestas por versos de metro regular rimados ${ }^{2}$,

1 Creemos que el mejor trabajo de conjunto sobre el villancico -o cantarcillo que, si bien autónomo en su nacimiento, solía colocarse como frontispicio o cabecera de un poema- es el de Sánchez Romeralo (1969). Véanse también, además de los manuales de retórica y versificación al uso (en bibliografía final), Rodrigues Lapa (1936), Saint Amour (1940) y, sobre todo, Le Gentil (1952: 209-243, 244-262, y 1954). En relación con el estribillo, pueden verse también, entre otros, Coelho (1912), Rodrigues Lapa (1934), Asensio (1953), Romeu Figueras (1950, 1954), Frenk Alatorre $(1966,1983)$ y Torner (1966), aunque más interesados en la técnica del paralelismo como fenómeno general, sus manifestaciones estróficas y otros aspectos de la lírica tradicional castellana.

2 No obstante, la rima predominante en la obra poética de E. Prados es asonante, y algunos poemas se componen en verso blanco; y la estrofa no se corresponde con la redondilla y la vuelta del villancico tradicional (compuesta ésta de dos mudanzas y simétrica aquélla a la cabeza), ni con la estructura del cuerpo del zéjel (un tríptico monorrimo y un verso de vuelta), ni de la canción medieval (una redondilla organizada en dos mudanzas biversales y una vuelta equivalente a la cabeza en el número de versos, la clase de rima y la disposión de ésta), cuyos esquemas métricos prototipos son: AA bbba ccca ddda..., para el zéjel (como principal forma de estribote); ABB cdcd (o cddc) dBB..., para el villancico; y abba cddc abba..., para la canción medieval (Baehr, 1962: 315-330; Domínguez Caparrós, 1993: 218-222). Las composiciones de Prados, como iremos viendo, responden más a una forma evolucionada de la canción paralelística. 
en abierta rebeldía contra el enardecido furor desatado, ya en esas mismas fechas, por el versolibrismo ${ }^{3}$ y las composiciones esquíticas, sin construcciones estróficas.

2. Como es de todos conocido, aquellas brevísimas y ligeras, cándidas, coplillas o cantarcillos de origen popular y casi siempre de transmisión oral conocidas comúnmente como villancicos (a veces, también refranes ${ }^{4}$ ), de autor desconocido y data tan remota como casi siempre incierta, emparentadas con las jarchas mozárabes y andalusíes que engalanaban -y determinaban- la moaxaja árabe o mudéjar ${ }^{5}$ y con las cantigas o canciones de amigo galaicoportuguesas, de estructura paralelística, generalmente irregulares en su forma métrica y, las más de las veces, de rima asonantada $o$, simplemente, sin rima, fueron, bien en su forma original bien retocadas con esmerado maquillaje, recuperadas y reutilizadas con extrema frecuencia por trovadores y escritores posteriores, sobre todo por los poetas del cancionero y de la corte y a partir del siglo XV, glosándolas o comentándolas a través de agrupamientos estróficos, normalmente homométricos (ritmo cuantitativo o silábico, ritmo de timbres o rima, etc., y número de versos).

Algunas de estas poesías o canciones que desarrollan y despliegan la grácil coplilla popular (el primitivo villancico), colocada al comienzo a guisa de fórmula de encabezamiento o leit motiv, con el tiempo se llamaron igualmente villancicos, y así se conocen también en nuestros días ${ }^{6}$, si bien más elaboradas, más artificiosas, menos puras, menos espontáneas y frescas: en efecto, tales villancicos, en manos de los poetas cultos, de épocas y periodos cualesquiera -del Renacimiento o del siglo XX...-, eran sazonadas con metro cuidado, perfecto, isosilábico -incluido el pie quebrado de algunos cantares- y rima consonante (es decir, más acordes con las formas poéticas del gusto cortesano, tales la cuarteta octosilábica

3 Ningún poeta del 27 logrará sustraerse por completo al fuerte envite del verso libre, de tan pujante cotización.

4 Existen, además, unas composiciones breves de estirpe francesa o provenzal, emparentadas formal y temáticamente con los villancicos, conocidas también por el nombre de refrains o refranes (Sánchez Romeralo, 1969: 364-380). La confusión terminológica es bastante habitual. De hecho, también se llaman comúnmente refranes los dichos sentenciosos o proverbios, y su relación con estos cantarcillos es tal, que muchos de ellos pasaron a la canción así como ciertos cantares fueron travestidos de "evangelios chicos" y moralejas (Frenk Alatorre, 1961 y 1997; Sánchez Romeralo, 1969: cap. 3).

5 Hay testimonios de jarchas escritas en árabe vulgar y en romance, o mezclando las dos lenguas. Muchas son canciones de amigo y presentan una estructura similar a la seguidilla y a la redondilla -y no tanto al zéjel primitivo y a su posible ascendiente más inmediato, la moaxaja, de estructura aún más compleja o sujeta a más constreñimientos-, por lo que es dable suponer que sean restos o desarrollos particulares de la más primitiva poesía lírica popular románica autóctona.

No obstante, las jarchas no siempre fueron cantarcillos populares preexistentes que el poeta tomaba para rematar su texto, sino que, con el tiempo, los mismos moaxajeros componían sus propias jarchas, de modo que muchas de ellas son coetáneas a las composiciones que les dan cobijo; en estos casos, es presumible que la moaxaja ya no se ajustara necesariamente al modelo métrico y temático que, para ella, representaba la jarcha.

Asimismo, las moaxajas no sólo se compusieron en lengua árabe, sino también en hebreo y romance; y las hay hispanohebraicas e hispanoarábigas.

Como la jarcha con respecto a la moaxaja (y, luego, al zéjel) -y la cantiga gallega o gallegoportuguesa-, el villancico dio pie al desenvolvimiento estrófico.

Sobre los orígenes de la lírica castellana en relación con las jarchas, así como con la moaxaja y el zéjel, véanse, entre otros, Millás Vallicrosa (1946), Stern (1948, 1951, 1953), Alonso (1949), Cantera (1949, 1957), García Gómez (1949, 1950a,1950b, 1956, 1965), Menéndez Pidal (1951), Frenk Alatorre (1952, 1953), Heger (1960), Sánchez Romeralo (1969: 343-364)...

6 Tal como figura, p. e., en los tratados y manuales de versificación. 
y la seguidilla, rigurosamente ceñidas al corsé métrico establecido), pero a veces también con una estructura más compleja y sofisticada, más trabadas y sujetas a un troquel de difícil fabricación, como el zejelesco y el paralelístico?.

\section{Una derivación de esta concepción artística, llamada a veces de "estribillo y cita",} consistirá en una composición de sistema iterativo, si bien con frecuencia descabezada de la coplilla de entrada (y, por tanto, más simple, al verse liberada de la servidumbre métrica y temática que ésta suele imponer); el originario villancico es reemplazado por otra estructura estrófica breve que se repite periódicamente o en intervalos regulares y acompasados en determinados momentos del poema (por ejemplo, los finales de estrofa), con mayor o menor vínculo temático y métrico con las estrofas restantes respecto de las cuales funciona

7 Ni siquiera en su origen todas estas composiciones poliestróficas de estructura fija (o estrofa cerrada) respetaron el modelo canónico y adoptaron una única forma. La creación de variantes y el cruce o mezcla de principios constructivos y códigos eran tanto o más frecuentes que los propios calcos literales del patrón métrico (véase n. 2). Como es de esperar, menos uniformidad habrian de guardar los hijos métricos que sus poco ortodoxos y a veces corruptos procreadores, de manera que no sólo surgirían poemas infieles respecto de su modelo compositivo, sino que proliferarían los casos fronterizos y las mixturas estróficas. Asi, el villancico de Cristóbal de Castillejo que tiene por tema el dístico "No pueden dormir mis ojos,/ no pueden dormir", aun cumpliendo a la perfección los requisitos del villancico clásico, comparte con la glosa el repetir, al final de cada estrofa o pie, el segundo verso del estribillo inicial, esto es, satisface el constreñimiento del reclamo rítmico de la rima que impone el esquema del villancico mediante la reproducción -glosa- literal de un verso. Otro tanto podría decirse del villancico que Cervantes incluye en el libro segundo de La Galatea, cuyo tema-estribillo reza como sigue: "En los estados de amor,/ nadie llega a ser perfecto,/ sino el honesto y secreto"; el tercer verso, con ligeras variantes impuestas por la sintaxis del verso encabalgante, se repite al final de cada estrofa.

La estructura canónica del villancico tradicional se va erosionando poco a poco, diversificando, en manos de los poetas cultos: de Lope de Vega es el que tiene por estribillo una redondilla encabezada por el verso "Déjate caer, Pascual" (cit. en Mayoral Ramírez, 1994: 216), cuyo cuerpo presenta dos pies de mudanza y vuelta diferentes (de versos octosílabos el primero y anisosilábicos el segundo), siendo la del segundo pie la única que "vuelve" a la rima del estribillo (además, el último verso de la segunda vuelta reproduce el cuarto verso del estribillo, por lo que, como en los poemas citados de Castillejo y Cervantes, se contamina de un procedimiento propio de la glosa). Poco tienen que ver con el villancico tradicional más genuino los poemas "El duende" y "Edipo", de Arjona y Martínez de la Rosa respectivamente, que aduce Navarro Tomás (1956: 337) o el de Juan Ramón Jiménez que se abre con el verso "La fuente aleja su cantata" y que tiene por estribilio, con variantes léxicas, el dístico ";Mar de la aurora, mar de plata: qué limpio estás entre los pinos!" (cit. en De Balbín Lucas, 1962: 335). Muchas letrillas, como las conocidas "Poderoso caballero" y "Ándeme yo caliente", de Quevedo y Góngora respectivamente, no son sino villancicos "de-generados".

Además de estos hechos propios de la evolución de las formas poéticas, de la continua pugna o vaivén entre la tradición y la originalidad, y de la falta misma de lindes o fronteras fijas e infranqueables entre los patrones constructivos, también es cierto que los estudiosos no siempre se ponen de acuerdo a la hora de clasificar un determinado poema; p. e., Quilis Morales (1984: 130-132) cita como zéjeles un texto de Alfonso Álvarez Villasandino que comienza con los versos-estribillo "Vivo ledo con razón,/ amigos, toda sazón" (núm. 41, Cancionaro de Baena) y otro de Gil Vicente que se abre con el estribillo "Dicen que me case yo,/ no quiero marido, no", cuando, de seguir la opinión de Baehr (1962: 316), habrían de describirse como rondeanx-virelais o rondeles al iterarse el estribillo tras cada estrofa (mudanza de tres versos monorrimos más vuelta de un verso, o, como supone Baehr, mundanza de un pareado rimado (bb) más mudanza de dos versos (ba) que riman el primero-verso de enlace métrico-con la mudanza y el segundo - vuelta- con el estribillo), aunque los dos tipos de poesías responden a la forma de estribote. Asimismo, la propuesta de Baehr (1962) basada en que el zéjel, frente al rondel, no itera la cabeza en calidad de estribillo contendería con la de Navarro Tomás (1956: 336) cuando critica a Arriaza que llame rondel a un poema suyo siendo, en opinión de Navarro Tomás, un zéjel: en efecto, el tema-estribillo ("Si amistad se vuelve amor, adiós, placer de la vida") se repite, si bien con una ligera variación (Si amistad... - Que amistad...), tras el cuerpo (mudanza y vuelta) del texto. Domínguez Caparrós (2002: 116-125) también muestra la distinta concepción que tienen tratadistas (Díez Rengifo, A. de Carvallo) y escritores sobre las formas métricas. 
como nexo estrófico: se trata del estribillo, una manifestación particular del paralelismo. Tal estribillo ya no funciona siempre como señal de apertura del texto, como el villancico popular, pues puede aparecer en medio del poema o después de cada estrofa, ni necesariamiente cierra el poema ${ }^{8}$. La técnica del estribillo se consolida y se aplica como un artificio novedoso a muy diversas composiciones poliestróficas que lo desconocían, e, incluso, al romance?. Esta versión moderna del ancestral villancico -o de la antigua canción paralelistica o cosaute, con la que parece guardar más parentesco ${ }^{10}-$, es, tal vez, la configuración poemática más cultivada por los escritores españoles del primer tercio del siglo XX: los hermanos Machado, Unamuno, Juan Ramón, Alberti, García Lorca, Guillén..., y Prados. De Emilio Prados son los textos "Nocturno inmóvil" y "Trinidad de la rosa (VI)" "1.

8 La repetición de un verso o grupo estrófico fue tratada por los clásicos ( $\mathrm{F}$. de Herrera, G. Correas, B. Jiménez Patón...) como una figura retórica, como una suerte de epimone (Lausberg, 1960; Frédéric 1985), si bien de orden textual, cuya posición en la estrofa determina su denominación: anáfora, epífora o epanáfora, complexión, epanalepsis, anadiplosis o cadena (Mayoral Ramírez, 1994: 208-213).

9 P. e., Lope de Vega intercala el estribillo "El cielo me condene a eterno lloro/ si no aborrezco a Filis y te adoro" en el romance octosilábico que comienza con los versos "Llenos de lágrimas tristes/ tiene Belardo los ojos/ porque le muestra Belisa/ graves los suyos hermosos" (cit. en Domínguez Caparrós, 1993: 232-233).

10 El cosaute, en su modelo más puro, exigía, como se ha dicho, la repetición literal, tras cada dístico monorrimo, del segundo verso del tema, que funcionaba como estribillo: "A aquel árbol que vuelve la foxa/ algo se le antoxa.// Aquel árbol del bel mirar/ face de maniera flores quiere dar/algo se le antoxa.// Aquel árbol del bel veyer/ face de maniera quiere florecer: / algo se le antoxa.// Face de maniera flores quiere dar: / ya se demuestra; salidlas mirar: / algo se le antoxa [...]" (D. Hurtado de Mendoza). Ni el zéjel, ni el villancico ni la canción medieval exigían tal requisito: sólo el cumplimiento del acuerdo en la rima, si bien no pocas veces se reproducían versos enteros o partes del cantarcillo de entrada. Es en estas ocasiones -cuando la repetición del estribillo es completa o casi completa- cuando los limites entre las distintas formas poéticas quedan algo desdibujados, tal como puede apreciarse en el zéjel de Gil Vicente, el villancico de Juan del Encina y la canción de Gómez Manrique que se citan, respectivamente, a continuación: “Dicen que me case yo;/ no quiero marido, no.// Más quiero vivir segura/ n'esta sierra a mi soltura,/ que no estar en ventura/ si casaré bien o no.// Dicen que me case yo,/ no quiero marido, no"; "Más vale trocar/ Placer por dolores,/ Qu'estar sin amores.// Donde es gradecido/ Es dulce morir; Vivir en olvido/ Aquel no es vivir// Mejor es sufrir/ Passión y dolores/Qu'estar sin amores", "Sabe Dios quánto porfio/ por vos poder desamar; / mas no me puedo tirar/ de ser más vuestro que mio.// Por vos fallar tan ingrata/ y contra de mi plazer/ querría non vos querer,/ pues esto solo me mata.// Pero soy tornado río,/ que no me puedo tornar/ aunque quiero, nin tirar/de ser vuestro más que mio". Con la equivalencia de las cabezas en el número de versos, en poco diferirían el villancico de Encina y la canción manriqueña si éstas se hubieran repetido por completo en las vueltas como genuinos estribillos. La indistinción es bastante general si, además de esta circunstancia, concurre el hecho de que el cuerpo de estrofa o mudanza tampoco acata la norma métrica impuesta por el patrón regular (tríptico monorrimo más verso de enlace rimante en el zéjel, redondilla en el villancico, redondilla en la canción). Dada esta situación caótica entre formas poéticas cuyo riguroso esquema métrico permitía diferenciarlas en su origen, la confusión de estas formas poéticas con el cosaute estará servida cuando éste altere la estructura de su mudanza (dístico monorrimo): en dos pareados, en una redondilla... Así las cosas, no es fácil aventurar cuál de todas estas composiciones de estrofa cerrada es la base de formación de la actual poesía de estribillo, si no cabe barruntar que en su creación hayan convergido todas, ya evolucionadas, o sea obra del secreto conjuro de varias. Cabe suponer también la existencia de una lírica hispánica primitiva de orden paralelístico sin tema o villancico que conviviera independientemente con todas estas estas formas poéticas de estructura métrica trabada articuladas en torno al villancico inicial, y que entre ellas se produjeran interferencias. P. e., Sánchez Romeralo (1969: 338-340) supone la fusión de la tradición paralelística con la técnica del villancico.

Sobre cl cosaute, además de los manuales de retórica y métrica, pueden verse Romeu Figueras (1950), Asensio (1953: 130-167 y 225-240) y Le Gentil (1952: II, 280-282).

11 Seguimos la edición Antología (1923-1953): Buenos Aires, Losada, 1954. 
Prado de la noche.

Altas alamedas.

La luna y la yerba.

Sobre el cuerpo de mi sombra; bien ajustado a mi sombra, mi cuerpo duerme en el suelo.

-Y ¿en dónde mi corazón?...

Buscando mis pensamientos.

Prado de la noche.

Altas alamedas.

La luna y la yerba.

Sobre la sombra, la noche, bien ajustada a su sombra, duerme en el cielo.

-Y ¿en dónde la luz del solo?... Alumbrando a los luceros.

Prado de la noche.

Altas alamedas.

La luna y la yerba.
¡En todo está! ipor todo va la rosa perenne y fiel en dar su fugaz símbolo al clamor de lo eterno...

¿En todo está! ipor todo va pasando, visitadora dueña maternal, la rosa!

La rosa sin espacio, en su equilibrio, inmóvil nace y va y entra y reposa sin dejar de pasar, transverberada.

¿En todo está! ipor todo va quedando, sin salir, sin entrar, sin ser apenas: viajadora constante de un tiempo corporal hueco de rosa!...

¡En todo está! jcon todo va llegando la rosa a ser la rosa y todo es ya, como su luz varada, figuración de mundo en pensamiento!

¡En todo está! ¡de todo está llegando la rosa a ser y todo es ya la rosa! iEn todo estál ;por todo va flotando su aurora, descuajada: incendio, herida, estela de la rosa!

¡En todo está!

destino fiel, ¡Con todo palpitando: amor,

feliz presencia, olvido...!

En todo preguntando la derramada vespertina rosa... ¿En todo navegando!

Con todo, si:

¡en todo está! ipor todo va cantando!... ¡Y, todo es por la flor, muerte sin sombra!

La nueva concepción poética del estribillo, como presunta evolución de la canción paralelística, altera las convenciones de ésta poniendo el acento en el enunciado o grupo estrófico iterativo, en el estribillo: se tiende a la repetición literal (léxica) y no sólo de rima 
(rítmica) del segundo verso del cantarcillo de entrada o del estribillo, cuando no de todo él completo (hecho que lo asimila a la $g l o s a^{12}$ ); las estrofas no son necesariamente pareados ni sus versos, monorrimos; y se cancela la vuelta, porque su función propia de enlace rítmico es desempeñada por el estribillo.

4. El estribillo llega a alcanzar una enorme relevancia artística en el conjunto de la composición. La importancia que se le concede al enunciado iterativo -y, concretamente, al estribillo- en la poesía paralelística se aprecia en distintos mecanismos constructivos, como es el caso del artilugio que podríamos llamar estribillo alternante: el escritor juega con dos estructuras iterativas, que se van sucediendo alternativamente. El estribillo alternante puede conseguirse bien mediante la repetición de un único enunciado (estribillo) con variaciones, como ocurre en "Nocturno fiel", del poemario Tiempo (1923-1925), bien con la conjunción de dos enunciados (estribillos) distintos, como ilustra "Jardín cerrado". En el primer texto, las dos variantes que presenta el dístico iterativo en virtud del diverso orden distributivo que adoptan los lexemas cielo y suelo van alternándose en las sucesivas recurrencias ${ }^{13}$; en el segundo texto, las estructuras iterativas que alternan son el estribillo monoversal "¡Ay, cuánta estrella cautiva!" (con variaciones léxicas) y el primer verso de cada estrofa biversal, "Para mirar mejor la noche", convertido en mera anáfora textual:

12 Si bien, en la glosa los versos de la coplilla inicial no se repiten en las ocurrencias distintas del estribillo como un grupo estrófico inseparable, sino que son diseminados en las distintas estrofas, generalmente en sus finales, como ilustra el poema de Lope de Vega (Rimas sacras) que tiene por estribillo la redondilla "Ven muerte tan escondida, que no te sienta venir,/ porque el placer del morir/ no me vuelva a dar la vida" y cuya primera glosa comienza con este juego de palabras: "Muerte, si mi esposo muerto, no eres Muerte, sino muerta" (cit. en Mayoral Ramírez, 1994: 219-220).

Sobre la glosa como forma poética, véánse, entre otros, García Gómez (1941), Janner (1943, 1946), Le Gentil (1952: II, 291-304) y Frenk Alatorre (1958), además de los manuales de métrica al uso.

13 E. Prados, en el texto "Vega en calma", del mismo poemario, utiliza el mismo procedimiento:

Cielo gris.

Suelo rojo...

De un olivo a otro

vuela el tordo.

(En la tarde hay un sapo

de ceniza y de oro.)

Suelo gris.

Cielo rojo...

Quedó la luna enredada

en el olivar.

¡Quedó la luna olvidada! 
Luna en el cielo.

Luna en el suelo.

El mar entra por la noche y la noche por el sueño...

Luna en el suelo.

Luna en el cielo.

Dando la mano a su sombra cruza el hombre por el tiempo...

Luna en el cielo.

Luna en el suelo.

Canta el olivar dormido

en los brazos del silencio...

Luna en el suelo.

Luna en el cielo.

Cierra la muerte sus alas sobre la espalda del viento.

Luna en el cielo.

Luna en el suelo.
Para mirar mejor la noche,

estoy parado a orillas de mi vida.

¡Ay, cuánta estrella cautiva!

Para mirar mejor la noche, estoy parado junto al agua dormida. iAy, cuánta estrella cautiva!

Para mirar mejor la noche, estoy parado a espaldas de la brisa.

¡Ay, cuánta estrella cautiva!

Para mirar mejor la noche, estoy parado al pie de una sonrisa.

¡Ay, cuánta estrella cautiva!

(iAy, cuánta estrella cautiva en el fondo de mi herida! ¡Ay, cuánta estrella cautiva coronando mi agonía!...)

Para mirar mejor la noche, estoy soñando junto al agua dormida.

iAy, cuánta estrella en la orilla!...

Para sentir mejor la noche, voy a arrancarle al surtidor su espina.

;Ay, cuánta estrella partida!

(Mueve el silencio las ramas...

Un jazmín cae sobre el agua...

¡Ay, cuánta estrella en mi alma!)

Para mirar mejor la noche,

voy a dormirme a orillas de la Nada.

Otro recurso de énfasis del estribillo consiste en reducir el cuerpo del texto a la mínima expresión, como ocurre en el poema "Trinidad de la rosa (III)", en el que la estrofa es monoversal; y lo mismo cabría decir de "Temblor de estío", si se considera que la única parte 
del poema que varía es el segundo verso de los pareados estróficos: en efecto, Emilio Prados vuelve a recurrir al estribillo alternante, el dístico monorrimo ¿Qué me importa la alameda/ si no he de volver a ella? que va enlazando las estrofas biversales y el primer verso de éstas, "Al borde de la alameda" (véase asimismo el poema antes citado "Jardín cerrado"):

Mirando al agua

la rosa

y junto a la rosa

yo,

mirando al agua.

(La luz era el alba.)

Mirando al agua

la rosa

y junto a la rosa

yo,

mirando al agua.

(El sol era un ascua.)

Mirando al agua

la rosa

y junto a la rosa

yo,

mirando al agua.

(La tarde empezaba.)

Mirando al agua

la rosa

y junto a la rosa

yo,

mirando al agua.

(¿Qué noche tan larga!)

Mirando al agua

la rosa

y junto a la rosa

yo,

mirando al agua.
¿Qué me importa la alameda

si no he de volver a ella?

-Al borde de la alameda

hay una rosa entreabierta...

¿Qué me importa la alameda si no he de volver a ella?

-Al borde de la alameda

hay un lucero que sueña...

¿Qué me importa la alameda si no he de volver a ella?

- Al borde de la alameda hay una sombra que espera...

¿Qué me importa la alameda si no he de volver a ella?

- Al borde de la alameda,

llora el agua entre las piedras...

¡Suspiran las hojas secas!

¿Qué me importa la alameda

si no he de volver a ella?

(iQué estrellas tan bajas!) 
Mirando al agua

la rosa

y junto a la rosa

yo,

mirando al agua.

(¡Qué azul vuelve el alba!)

Mirando al agua

la rosa

y junto a la rosa

yo,

mirando al agua...

Desde un punto de vista de la semiótica de la recepción, puede interpretarse como otro mecanismo de énfasis del estribillo el carácter periódico o cíclico con que aparece: cuando las estrofas son de extensión equivalentes y el estribillo se intercala en intervalos regulares, equidistantes, las expectativas de repetición suscitadas en el receptor son mayores, como parece ocurrir en los dos poemas precedentes ${ }^{14}$, frente a la impresión que provoca el poema compuesto de estrofas desiguales en el que el estribillo irrumpe de manera irregular o desacompasada. Este "descompás" o desequilibrio estrófico era también conocido por la antigua poesía tradicional castellana. Dicho contraste puede así mismo apreciarse comparando los textos "Llanuras de sol" y "¿Todo se ha perdido?..."

14 Igualmente, en los poemas "Llanuras de sol", "Nocturno inmóvil", "Nocturno fiel" o "Cruz del cuerpo", entre otros.

15 El poema "Dormido en la yerba" muestra, si cabe, una irregularidad aún mayor; son tres enunciados los que se repiten al menos dos veces sin guardar, en general, ningún tipo de paralelismo absoluto ni frecuencia de aparición definida:

Todos vienen a darme consejo.

Yo estoy dormido junto a un pozo.

Todos se acercan y me dicen:

- La vida se te va,

$y$ tú te tiendes en la yerba,

bajo la luz más tenue del crepúsculo,

atento solamente

a mirar cómo nace

el temblor del lucero

o el pequeño rumor

del agua, entre los árboles.

Y tú te tiendes sobre la yerba:

cuando ya tus cabellos

comienzan a sentir

más cerca y fríos que nunca,

la caricia y el beso

de la mano constante

y sueño de la luna.
$Y$ ti te tiendes sobre la yerba:

cuando apenas si puedes

sentir en tu costado

el húmedo calor

del grano que germina

y el amargo crujir

de la rosa muerta.

$Y$ tú te tiendes sobre la yerba:

cuando apenas si el viento

contiene su rigor,

al mirar en ruina

los muros de tu espalda,

$y$, el sol, ni se detiene

a levantar tu sangre del silencio.

Todos se acercan y me dicen:

- La vida se te va.

Tú, vienes de la orilla

donde crece el romero y la alhucema 
Campo, campo y más campo...

$-¿ Y$ el olivar?

(Mi corazón, soñando.)

Campo, campo y más campo.

(¿Qué me persigue, Dios, qué me persigue?...)

Campo, campo y más campo...

-Y ¿dónde el mar?

(Mi corazón, llorando.)

Campo, campo y más campo.
iAy, sombra, sombra,

búscame por el fuego!

Me acerco a la mariposa:

¡está al fondo del estanque!

Me acerco al árbol más bello:

¡está al fondo del estanque!

Me acerco al niño que juega:

¡está al fondo del estanque!

Me acerco al alma, en silencio:

¡está al fondo del estanque!...

iAy, sombra, sombra,

búscame por el fuego!

Vi la tarde abierta,

quise entrar en ella.

¡Buscaba el alivio

de otras tardes, muertas!

Un jazmín cantaba

su aroma de estrella...

-¡Ay, jazmín!...

Me acerco:

su flor está en tierra.

Un árbol soñaba

toda una alameda.

Todos vienen a darme consejo.

Yo estoy dormido junto a un pozo.

Sólo, si algún amigo

se acerca, $y$, sin pregunta,

me da un abrazo entre las sombras:

lo llevo hasta asomarnos

al borde, juntos, del abismo,

$y$, en sus profundas aguas, ver llorar a la luna y su reflejo, que más tarde ha de hundirse como piedra de oro, bajo el otoño frío de la muerte. 
Me acerco...

Sus ramas,

sobre el suelo, secas...

Era un ascua el pájaro, ¡luz de primavera!

Me acerco...

Sus alas:

ceniza en la yerba.

¡La yerba! ¡la yerba!

¡Oh final ternura!

(Me arrodillo en ella...)

;Ay, sombra, sombra,

buscame por el fuego!

Aún me queda una esperanza:

¿no seré yo el que está muerto?

;Ay, sombra, sombra,

búscame por el fuego!

Teniendo en cuenta la posición estratégica de que, desde un punto de vista artístico, gozan los comienzos y finales de texto, no cabe duda de que otro recurso formal de encarecimiento del estribillo basado en la repetición es su empleo como sistema de apertura y cierre textual a la vez, de modo que el poema adquiere un carácter circular, cerrado, con clausura hermética, $o$, cuando menos, como señal de inicio, asumiendo la función del villancico tradicional. Carente el interior del texto de ese privilegio, el estribillo exclusivamente medial no puede producir tales efectos; compárense, a modo de ejemplo, los poemas "Nivel del puerto", con repetición en los extremos y el medio, y "Soledad", con solo repetición interior ${ }^{16}$ :

Palma, cristal y piedra.

El nácar del perfil puro del gesto,
Latiendo estaba el silencio, cuando se acercó la luna por el cielo...

\footnotetext{
16 Adviértase, además, que el sentimiento de estribillo decrece cuanto menor es el número de ocurrencias. En "Soledad", el enunciado iterativo sólo aparece en dos ocasiones.

Son numerosos los poemas en los que E. Prados practica la técnica del cerramiento absoluto o hermético mediante la repetición, al comienzo y al final del poema, del estribillo: "Llanuras de sol", "Monte oscuro", "Trinidad de la rosa (II)", "Nocturno fiel", "En la media noche", "Jardín cerrado", "Nocturno inmóvil", "¿Todo se ha perdido?", "Temblor de estío", "Cruz del cuerpo", "Dormido despierto"...; no obstante, en algunos poemas (como los dos últimos citados) el autor provoca la ruptura del cierre mediante la repetición no exacta del estribillo (véase infra).
} 
enérgico en el agua.

Extractada la brújula, sostiene al equilibrio vertical sobre el viento...

(El imán se detiene.)

Palma, cristal y piedra.

Por el muelle, despacio, la memoria, indolente, se apoya en la baranda de un crepúsculo fácil. El sueño se devana y se humedece el tiempo al entregar su cinta...

(Se rinde el movimiento.)

Palma, cristal y piedra.

Por el muelle del día, pierde pie la memoria... La mirada, se vierte líquida, en el olvido.

(El alma se separa y la fior sube al cielo...)

¡Palma, cristal y piedra!
(La sombra se estaba abriendo.)

Exánime está el silencio.

$\mathrm{Y}_{\text {¿dónde se fue la luna }}$

por el cielo?...

(La sombra se estaba abriendo.)

-¿Quién va?...

(Sobre el horizonte, se está desangrando el agua

a borbotones.)

Otro procedimiento de realce del estribillo es de índole tipográfica, y consiste en aislarlo tipográficamente del cuerpo del poema mediante espacios blancos interlineales; de esta manera se consigue al mismo tiempo perfilar el contorno de los distintos grupos estróficos, tal como ilustra la mayoría de los ejemplos citados. El destacamiento tipográfico del estribillo no es sino un recurso "visual" para controlar la lectura del receptor. Cuando el enunciado iterativo constituye un verso más del grupo estrófico, no obstante ubicado normalmente en una posición prominente, resulta menos perceptible a los ojos del lector, enmarañado o enredado aquél en el tejido del texto, difuminado. Compárense, por ejemplo, "Bajo el ciprés" y "Canción"17:

17 Como hemos visto, en "Jardín cerrado" y en "Temblor de estío" uno de los enunciados iterativos que dan lugar al estribillo alternante o doble está dentro del cuerpo del poema: el primer verso de estrofa. En los textos "Cuando era primavera", "En la media noche" y "Dormido en la yerba", los enunciados-estribillo tampoco aparecen destacados tipográficamente mediante su aislamiento espacial, sino incursos en los grupos estróficos, si bien ocupando las posiciones de principio y fin de estrofa los dos primeros (conforman una variedad retórica de la 
complexión) y sólo el comienzo el segundo (anáfora). En la medida en que, en los dos primeros poemas, son dos los versos repetitivos que concurren en cada eslabón estrófico, cada una de las estrofas presenta un carácter cerrado o circular, frente a lo que ocurre en "Canción" -aun también con dos enunciados iterativos: uno al comienzo (No es lo que está roto, no) y otro en el medio (lo que está roto es $+\mathrm{SN}$ )- y en "Dormido en la yerba":

\section{Cuando era primavera en España:}

frente al mar, los espejos rompían sus barandillas y el jazmín agrandaba su diminuta estrella, hasta cumplir el límite de su aroma en la noche... ¿Cuando era primavera!

Cuando era primavera en España: junto a la orilla de los ríos, las grandes mariposas de la luna fecundaban los cuerpos desnudos de las muchachas y los nardos crecían silenciosos dentro del corazón, hasta taparnos la garganta... ¡Cuando era primavera!

Cuando era primavera en España: todas las playas convergían en un anillo y el mar soñaba entonces, como el ojo de un pez sobre la arena, frente a un cielo más limpio que la paz de una nave, sin viento, en su pupila. ¡Cuando era primavera!

Cuando era primavera en España:

los olivos temblaban adormecidos bajo la sangre azul del día, mientras que el sol rodaba desde la piel tan limpia de los toros, al terrón en barbecho recién movido por la lengua caliente de la azada. ¡Cuando era primavera!

Cuando era primavera en España:

los cerezos en flor se clavaban de un golpe contra el sueño y los labios crecian, como la espuma en celo de una aurora, hasta dejarnos nuestro cuerpo a su espalda, igual que el agua humilde de un arroyo que empieza... ¡Cuando era primavera!

Cuando era primavera en España: todos los hombres desnudaban su muerte y se tendian confiados, juntos, sobre la tierra, hasta olvidarse el tiempo y el corazón tan débil por el que ardían... ¡Cuando era primavera!
Hubiera preferido, nacer con los ojos quemados por la luz del desierto anterior a mi sangre, que no ver hoy mi vista igual que lágrimas culpables, gota tras gota, estéril, perderse bajo tierra igual que trigo muerto, porque no es justo acariciar lo que se ama.

Hubiera preferido, nacer con los labios fundidos, como las aguas

que nunca han de brotar y profundas se mezclan al corazón oscuro de la sombra, a no sentir mis besos bajo el olvido deshacerse $y$ esconder perseguidos el ardor de su carne, entre las hojas del recuerdo, porque no es justo acariciar lo que se ama.

Hubiera preferido, nacer tras el vacío superior de la Nada: en su sueño, bajo el ancho misterio de la campana silenciosa y densa de su espacio, a no sentir la flor del azahar como una herida incandescente en el hueso del alma, $y$ ver la roja fruta del naranjo, en sazón, amarga sobre el suelo frente al lucero que tapado la mira, porque no es justo acariciar lo que se ama.

\section{Hubiera preferido, nacer}

a espaldas de la muerte, bajo ese enorme mar ilimitado, donde sólo la forma de un caracol de sal recoge como un eco en su concha, la angustia sin tejer, de la espuma, a no sentir, cómo el ala del pájaro sin cantar, sobre el árbol se desjhace; mientras mi oído sobre el agua sólo escucha a los peces en su sonámbulo vagar 
En el huerto me he dormido.

Árbol sin nacer: ¿qué olvido futuro, será tu sombra?

Árbol de ayer: ¿en qué sueño, tu olvido su mano ahonda?...

En el huerto he despertado.

Morado alhelí: ¿qué fuego quema tu aroma lejano? Jazmín -temblor de la noche-: ¿qué fuente te está llamando?

En el huerto estoy sentado.

Cuerpo triste: ¿en qué rocío tu pena se está mojando?... (Huele el sándalo florido y mueve el viento el maestranzo. (Flota la luna en la acequia...) En el huerto estoy llorando.

Cuando era primavera en España: yo buscaba en el cielo, yo buscaba

las huellas $\tan$ antiguas de mis primeras lágrimas y todas las estrellas levantaban mi cuerpo siempre tendido en una misma arena, al igual que el perfume, tan lento, nocturno, de las magnolias... ¿Cuando era primavera!

Pero, jay!, tan sólo cuando era primavera en España. ¿Solamente en España, antes, cuando era primavera!
No es lo que está roto, no, el agua que el vaso tiene: lo que está roto es el vaso $\mathrm{y}$, el agua, al suelo se vierte.

No es lo que está roto, no, la luz que sujeta al día: lo que está roto es el tiempo y en la sombra se desliza.

No es lo que está roto, no, la sangre que te levanta: lo que está roto es tu cuerpo $y$ en el sueño te derramas.

No es lo que está roto, no, la caja del pensamiento: lo que está roto es la idea que la lleva a lo soberbio.

No es lo que está roto Dios, ni el campo que Él ha creado: lo que está roto es el hombre que no ve a Dios en su campo.

entre las ondas,

porque no es justo acariciar lo que se ama.

Porque no es justo acariciar lo que se ama: duermo y duermo, ya siempre con los ojos abiertos, como la luna nace sin saber si ya es beso de la sombra la luz de su cuchilla, o es sólo su reflejo de oro, nueva herida en el cielo, con la que ha de salvar la noche misma en la que duerme.

Habrá podido advertirse que E. Prados no clausura el poema de forma simétrica: el primer texto es rematado con un estrambote tetraversal que incluye en su interior los versos iterativos (los cuales, en realidad, representan un mismo enunciado oracional, sólo que el segundo queda acortado con la supresión del complemento locativo en España); la segunda composición se cierra con una estrofa que reproduce sólo el segundo de los versos iterativos que, justamente, ocupa el lugar del primero (comienzo de estrofa), dando lugar a una suerte de encadenamiento textual o anadiplosis. 
¿Por qué me llamas dormido, compañero?

\section{-Porque cuando miras}

al agua del río

y yo, al agua miro:

por el agua misma del río

siento que te pierdo.

$Y$ pregunto a la adelfa

$y$ al junco pregunto

y al lirio del huerto,

si te han visto pasar

y me dicen:

-Tan sólo sentimos,

un roce en el viento.

¿Por qué me llamas dormido, compañero?

-Porque cuando miras

al sol, que transpone

la herida del día,

y se hunde en la sangre del cielo

y más tarde, en la noche,

para darle a la luna más vida

y más oro al lucero:

por la sangre del tiempo, encendida, siento que te pierdo.

$Y$ pregunto a las hojas marchitas

bajo la alameda,

$y$ al agua que duerme en la fuente

pregunto,

y al jazmín abierto,

si te han visto pasar

$y$ me dicen:

-Tan sólo sentimos,

un roce en el viento.

¿Por qué me llamas dormido,

compañero?
La luna estaba

en el alba.

No lo sabía...

Le dijo la luna

al agua:

-Mira,

la flor, con mi luz, parece el alma de mi luz:

jel alma mía!

Le dijo la luna

al agua.

(El agua no comprendía.)

Todo era calma,

silencio...

La Eternidad sonreía.

El sol mojaba

a la luna

y una rosa parecía.

Le dijo el agua

a la flor:

-Mira,

la luna sobre mi espejo

parece el alma de mi luz:

jel alma mía!

Le dijo el agua

a la rosa.

(La rosa no comprendia.)

Todo era paz,

hermosura...

La Eternidad sonreía.

La rosa estaba

en el alba.

La luna no lo sabía. 
-Porque cuando miras

mi cabeza doblada en mi pecho

y en mis ojos la brasa del llanto:

en mis propios ojos

siento que te pierdo.

$Y$ pregunto a la flor de mis párpados,

$y$ a su lluvia sin nubes pregunto

-tormenta en mi cielo-,

y pregunto a mi mano

mojada en mis lágrimas,

si te han visto pasar

$y$ me dicen:

- Tan sólo sentimos

un roce en el sueño...
Le dijo la rosa

al viento:

- Mira,

la luna bajo mi aroma

parece el alma de mi olor:

jel alma mia!

Le dijo la rosa

al viento.

(El viento no comprendia.)

Todo era luz de misterio.

La Eternidad sonreía.

¿Y por eso me llamas dormido?...

¿Compañero!

El valor preferente que Emilio Prados concede al estribillo se manifiesta igualmente cuando compone textos de acuerdo con un diseño constructivo trabado basado en la conjunción orquestada de distintas estructuras iterativas, lo que, en términos retóricos, cabría calificar de epímone múltiple. Uno de estos diseños, aunque más simple, es el comentado estribillo alternante que daba forma a poemas como "Temblor de estío" o "Vega en calma". Tres o más secuencias o estrofas repetitivas se combinan en los textos "Dormido despierto" y "Amor", que se citan a continuación: tanto uno como otro presentan una estructura dividida en tres núcleos equivalentes, fragmentados, a su vez, en grupos estróficos simétricos iterativos organizados armoniosamente siguiendo un orden correlativo o secuencial ${ }^{18}$ :

18 Son muchos otros los textos que presentan una estructura trabada, como el comentado "Nocturno inmóvil", en el que las dos partes tipográficamente separadas de cada quintilla (xxa xa), delimitadas por el estribillo intermedio, guardan un paralelismo casi perfecto (métricamente roto por el pie quebrado del tercer verso de la segunda estrofa) gracias a la repetición de las estructuras sintácticas y léxicas de los enunciados escanciados en las dos líneas versales: Sobre $+\mathrm{SN} /$ bien ajustado $(a)$ a + pos. + sombra / [mi cuerpo] duerme en el $+\mathrm{N} / /-Y$ ¿en dónde $+\mathrm{SN} .$. / ger. $+\mathrm{SN}_{\mathrm{CD}}$ " "Trinidad de la rosa (IV)" es otro ejemplo, sólo que los grupos estróficos que se reiteran a lo largo del poema (Estaba la rosa + complemento, ; Ay rosa,/la rosa fría! y El hombre no la miraba: / iba pensando en su dicha), el primero de ellos con variaciones continuas (en nieve-muera - abierta) y los otros dos con cambios en una sola ocasión (la rosa fria - la rosa viva, El hombre no la miraba - Y el hombre no la miraba), no concurren con el carácter cíclico con que aparecía el enunciado iterativo en "Nocturno inmóvil", en "Bajo el ciprés" o en "Canción", dado que se intercalan breves estrofas sin correspondencia simétrica, ajenas a los tres esquemas iterativos, ni con la misma regularidad o alternancia (el tercer grupo estribillístico se repite dos veces consecutivas): 
Como puede apreciarse, el principio constructivo de la repetición se corresponde más con un elaborado juego de paralelismos que con el ritmo de vaivén del estribillo; la forma repetitiva del estribillo parece haber sido reemplazada por la forma repetitiva del paralelismo, basada en la reiteración de esquemas sintácticos. No obstante, en el primer texto, sí se repite literalmente, como un auténtico estribillo, el primer conjunto estrófico (¿Por qué me llamas dormido,/ compañero?), el primero y último versos del segundo (-Porque cuando miras, siento que te pierdo) y parte del tercero ( $Y$ pregunto a.../ $y$... pregunto/ [...]/ si te han visto pasar/y me dicen: / Tan sólo sentimos, / un roce en el viento) de cada núcleo; y, en el segundo, se repiten íntegramente el tercero y último de la estrofa segunda ( - Mira, jel alma mia!) y el último de la quinta (La Eternidad sonreía), así como partes de otros versos (Le dijo $+\mathrm{SN},(\mathrm{SN}+$ no comprendia. $)$, Todo era $+\mathrm{N})^{19}$. Estos versos repetidos siguen cumpliendo algunas de las funciones del estribillo, como servir de nexo interestrófico y señalizar el contorno de las estrofas: por ejemplo, el dístico ¿Por qué me llamas dormido,/ compañero? marca el comienzo de cada núcleo estrófico de "Dormido despierto" y el enunciado $L a$ Eternidad sonreia, el final de los tres núcleos de "Amor".

5. En las formas poéticas tradicionales que adoptan el cantarcillo inicial (canción medieval, cosaute, villancico, zéjel, glosa...), el estribillo podía repetirse íntegramente-como en la mayoría de las primitivas composiciones ortodoxas con el modelo métrico o que siguen el orden canónico- o no -como en numerosas obras tardías, más libres e innovadoras-. Con estos precedentes, en las nuevas creaciones poéticas con estribillo la repetición también podrá ser total o parcial según afecte a todos los componentes lingüísticos y métricos o sólo a algunos de ellos.

La reproducción no literal, desde una visión estrictamente textual, permite introducir nuevos elementos temáticos y facilitar la progresión del hilo narrativo, o bien, atendiendo a otras perspectivas (semántica, estilística, pragmática...), producir determinados efectos

El hombre no la miraba:

iba pensando en su dicha.

La memoria de la rosa, sin nombre, el olvido hundía...

Y el hombre no la miraba: iba pensando en su dicha.

Todo el dolor de la rosa se fue cuajando en el día. Todo el olor de la rosa sonaba a tierra perdida.

Estaba la rosa muerta...
iAy rosa,

la rosa fría!

La rosa sin viento:

el sueño de la hermosura, sin vida...

$Y$ el hombre no la miraba iba pensando en su dicha.

Estaba la rosa abierta.

iAy rosa,

la rosa viva!

Todo el color de la rosa se hizo razón de su huida

19 Existen también reiteraciones léxicas. De hecho, el carácter cohesionado del poema "Amor" se debe, entre otras razones, a la forma encadenada con que se suceden los lexemas repetidos (especialmente los estadios 2-4): luna - luna/agua - luna/agua-agua ( $1 .^{\circ}$ núcleo) / luna/rosa-agua/flor-agua/rosa-rosa (2. núcleo)/ rosa/luna - rosalviento - rosalviento - viento ( $3 .^{\circ}$ núcleo). 
semánticos y expresivos (intensificación, frustración de expectativas, extrañamiento, sorpresa, placer estético, etc.). En la lírica contemporánea, parece existir una fuerza mayor que empuja a hacer del estribillo un elemento de juego y transgresión: se comprueba, en efecto, que el estribillo no siempre conserva su forma, sino que, antes al contrario, propende a modificarla..., reflejo, al fin y al cabo, de la esencia literaria: en todos los estilos artísticos siempre contienden dos fuerzas antagónicas, la tradición y la innovación, la inercia conservadora y el ímpetu original, lo viejo y lo nuevo.

La modificación del estribillo practicada por E. Prados es a veces simple, pues afecta a un único parámetro (la sintaxis, el léxico, la rima, la forma gráfica, la tipografía versal...); en cambio, el señalamiento de la violación de la estructura originaria es, con extrema frecuencia, múltiple, en la medida en que intervienen simultáneamente varios mecanismos de naturaleza diversa. Hemos visto que, en "Llanuras de sol", variaba la puntuación final del verso iterativo (alternaban el punto seguido y los puntos suspensivos), y, en "Nocturno fiel", el orden sintáctico de los lexemas cielo y suelo; que en "Jardín cerrado" (a partir de la mitad del texto) y "Bajo el ciprés", se producían cambios fundamentalmente léxicos y sintácticos ( Ay, cuánta estrella cautiva! - ¡Ay, cuánta estrella en la orilla! - iAy, cuánta estrella partida! - iAy, cuánta estrella en mi alma! / me he dormido - he despertado - estoy sentado - estoy llorando), y lo mismo cabría decir del poema "Caminante del sueño", citado más abajo (Morir sin ti-Morir alli - Morir en ti).

La transgresión de la norma que representa el genuino estribillo en cuanto repetición exacta o total $\multimap$, dicho de otra manera, del principio constructivo del paralelismo- no es azarosa, sino completamente deliberada; no es casual, sino matemáticamente calculada: responde a un plan o diseño constructivo previamente planificado por el escritor.

Este quebrantamiento de la norma que supone la repetición exacta del estribillo se pone especialmente de relieve en los finales de texto ${ }^{20}$, sobre todo cuando el patrón estructural que instaura el estribillo de la cabecera ha sido rigurosamente respetado en las sucesivas apariciones mediales, en cuanto la repetición exacta o literal imprime un ritmo de progresión con carácter indefinido, interminable. En virtud del principio de recursividad, un elemento repetido invita a esperar la producción de otro idéntico: cada uno de los eslabones de la cadena ininterrumpida de iteraciones perfectas va poco a poco fraguando y aumentando, en el receptor, la previsión de una nueva repetición cabal. En estos casos de previsibilidad máxima, la alteración del esquema iterativo al final del texto, por muy leve que sea, representa un corte brusco, la suspensión de la espera, el término de la serie repetitiva, la clausura del texto. El efecto que el escritor persigue con esta técnica de repetición recurrente y progresiva es acrecentar en el lector las expectativas de repetición, de nuevas repeticiones: cabe suponer que, cuanto mayor sea el número de ocurrencias cabales, mayores serán los índices de predicibilidad de una nueva repetición literal. Por ello, cuando el poeta sospecha que la ilusión de repetición que alberga el lector es muy grande o está saturada, provoca súbitamente la ruptura mediante algún artilugio artístico: conmutación léxica, cambio de tipografía versal, desacuerdo rítmico... Con la ruptura del modelo iterativo o estribillo al final del texto, el autor no sólo pretende marcar eficazmente el cierre absoluto del mismo

20 Sobre este procedimiento artístico, véanse especialmente Herrnstein Smith (1968) y García-Page (1988: cap. 2, y en prensa), y la bibliografía citada en este último. 
(en cuanto mecanismo textual intrínseco), sino desbaratar violentamente los cálculos y barruntos de repetición total (en cuanto recurso estilístico), es decir, crear en el lector sorpresa y goce estético.

Conocedor el poeta de estos efectos, tal procedimiento artístico ha sido empleado con mucha frecuencia en la poesía del siglo XX, y Emilio Prados, precisamente, lo utiliza en diversas ocasiones, como en "Cruz del cuerpo", mediante la conjunción de varios tipos de modificación lingüística (léxica, sintáctica, fónica, gráfica: Que corra y corral la luz por el agua - ¿Que corra y corra?/ ;La luz, sobre el agua!) y "Monte oscuro", incrustando versos ajenos en la última ocurrencia del estribillo (( Qué despacio/ va el agua al río, qué despacio! $\left.)^{21}\right)$ :

21 No obstante, hay también una variación tipográfica, puesto que el primer verso del estribillo, junto con el grupo estrófico intruso a él encabalgado, se aísla del resto mediante un blanco interespacial. Además, ese primer verso contiene otra variación morfológico-sintáctica que podría ser aviso del cierre: perífr. ger. ${ }_{\text {pte. }}$ (está cayendo) está viniendo) - V léxico ${ }_{\text {dud. }}+\mathrm{SP}$ (entró en el campo). El autor parece querer advertir al lector del valor secundario de este complemento estrófico, cual simple estructura parentética, señalizándolo simplemente con las balizas gráficas de los paréntesis.

Prados practica en otros poemas la ruptura del verso iterativo al final del texto o en su última ocurrencia, como en los citados "Nivel del puerto", mediante un simple cambio de entonación (Palma, cristal y piedra - iPalma, (ristal y piedra!), y "Canción", mediante básicamente un cambio léxico y sintáctico (No es lo que está roto, no - No es lo que está roto Dios). El segundo verso de esta última estrofa, además, representa también una ruptura con el modelo paralelístico: [det. $\left.+\mathrm{N}+\mathrm{O}_{\text {rel. }} / \mathrm{SP}\right] \mathrm{SN}$ (suj. de roto) $-n i+\left[\right.$ det. $\left.+\mathrm{N}+\mathrm{O}_{\text {rel.] }}\right] \mathrm{SN}_{\text {(suj. de resto coord a bioss) }}$ En "Amor" el cierre textual viene marcado por la ruptura de la simetría métrica al reducir caprichosamente a dos el último tríptico estrófico del tercer núcleo poemático: el carácter arbitrario del escanciado versal, esto es, la estudiada voluntad de ruptura del modelo, puede comprobarse fácilmente restaurando la simetría mediante la segmentación del primer verso octosilábico en dos quebrados de cinco y cuatro pies, similar a su anterior ocurrencia: Todo era luz de misterio./ La Eternidad sonreía - Todo era luz/ de misterio./ La Eternidad sonreia.

Aparte de en "Monte oscuro", el injerto como mecanismo transgresor aparece también en poemas como el citado "Temblor de estío", si bien el incremento estrófico no se produce en el estribillo de cierre, sino en la última estrofa: dístico monorrimo (aa) > tríptico monorrimo (aaa). En "Jardín cerrado" la simetría de los pareados se quiebra también en dos ocasiones: con una estrofa tetraversal que incluye dos veces el verso-estribillo ( $(\mathrm{A} A$, cuanta estrella cautival en el fondo de mi heridal/ ; Ay, cuánta estrella cautiva/ coronando mi agonia!)) y con un pareado monorrimo ((Mueve el silencio lás ramas.../ Un jazmin cae sobre el agua)). En este útlimo texto, Prados vuelve a recurrir a la señalización gráfica del comentario parentético utilizada en "Monte oscuro".

Similar a la técnica del injerto, podría considerarse la adición al final del texto, a modo de estrambote o coletilla, de una breve estrofilla que rompe el diseño paralelístico del poema. Así, la şimetria estrófica de la composición "Cuando era primavera", conseguida mediante la repetición estribillística del primero y último versos de grupos estróficos casi equivalentes en extensión (entre hexaversales y decaversales), queda bloqueada al incorporar el estrambote tetraversal $\sin$ que los enunciados-estribillo ocupen los lugares asignados en las estrofas precedentes. Algo semejante ocurre en el poema "Dormido despierto": la armoniosa simetría paralelística de los tres núcleos estróficos en que se articula el texto queda cancelada al retomar el autor el estribillo que encabeza cada uno de dichos núcleos, sin prosecución del resto de elementos iterativos. Ahora bien, no se destruye el carácter cerrado que otorgaba al texto la técnica paralelística, sino que ha sido ponderado mediante la citada vuelta al estribillo, y aun reforzado por los cambios lingüísticos en él operados (¿Por qué me llamas dormido,/ compañero? - ¿Y por eso me llamas dormido?.../ (Compañero!): el enunciado tiene ahora el valor de epifonema, de broche. La repetición exacta hubiera suscitado la ilusión de continuidad; la repetición inexacta, en la forma conseguida, provoca el sellado instantáneo, la clausura definitiva, y crea un cierre circular. 
Que corra y corra la luz, que yo duermo; que corra y corra la luz por el agua.

¡Ay, luna del rocío, bajo la sombra: las ramas se menean, las hojas lloran!

Que corra y corra la luz, que yo duermo.

Que corra y corra la luz por el agua.

¿Que la noche me llama! ¡Cómo me duele el frío de sus lágrimas sobre las sienes!

¿Que corra y corra la luz, que yo duermo.

Que corra y corra la luz por el agua.

Es mi cielo la tierra; mi cruz el cuerpo; mi lanzada la luna, mi suerte el sueño.

Que corra y corra la luz, que yo duermo.

Que corra y corra la luz por el agua.

¡Ni los clavos me faltan! (iCómo sujetan, los labios de una rosa, sobre la tierra.)

Que corra y corra la huz, que yo duermo.

Que corra y corra la luz por el agua.
La tarde ya está cayendo...

$Y$ el viento:

mueve que mueve al romero.

iEl viento!

- ¡Ay, qué grande es todo el cielo sin viento!

La noche ya está viniendo...

$Y$ el viento:

mueve que mueve al romero.

¡El viento!

- - Ay, cómo luce

el lucero sin viento!

La noche, ya entró en el campo...

(iQué despacio

va el agua al río,

qué despacio!)...

$Y$ el viento:

mueve que mueve al romero.

¡El viento! 
¿Dos ojos y unos labios

han suspendido,

al tiempo, por la noche, sobre el olvido?

Que corra y corra la luz, que yo duermo.

Que corra y corra

la luz por el agua.

Es mi sueño una fuente.

¡Brote la espuma!

(Sobre el arroyo, el río

y el mar, la luna.)

Que corra y corra la luz,

que yo duermo.

¿Que corra y corra?...

¿La luz, sobre el agua!

Si consideramos que el poema "Caminante del sueño" contiene dos estructuras repetitivas, el dístico monorrimo de cabeza y el verso repetido con variantes ya comentado ( $-; M i$ campo! ¿Morir sin ti?), y, por tanto, dos estructuras de cierre envolventes -el conjunto paralelístico con carácter cerrado, compuesto por las tres ocurrencias del estribillo monoversal (que abren y cierran dicho conjunto) y las dos estrofitas biversales alternantes del interior queda arropado o envuelto por el supuesto estribillo de entrada que es repetido al final absoluto del poema-, es evidente que la impresión de cierre hermético es más fuerte:

Por el camino del sueño,

campo y huerto.

- ¿Mi campo! ¿Morir sin ti?...

(Junto a la alberca, el jazmín

se enreda al ciprés del huerto.)

- Mi campo! ¡Morir alli!...

(Al pie del mastranzo en flor,

¿seguirá el agua corriendo?)

- ¡Mi campo! ¡Morir en ti!...

Campo.

Campo y huerto,

por el camino del sueño. 
Ahora bien, la clausura definitiva del texto viene marcada por la estrofa final, la vuelta al encabezamiento: en una lectura lineal, el verso-estribillo - iMi campo!..., con sus cambios constantes, no permite hacer sino una previsión de cierre indefinido, de continuidad ilimitada; de ahí que la irrupción imprevista del enunciado que encabeza el texto marque un corte brusco, una ruptura de la cadena iterativa, mas no necesariamente el final absoluto: el término se consigue fundamentalmente porque la recuperación del dístico inicial no es perfecta, porque no es exacta la repetición: por un lado, se invierte el orden de los versos (Por el camino del sueño, / campo y huerto - Campo y huerto, / por el camino del sueño) y, por otro, se añade, simultáneamente, un nuevo lexema y un nuevo verso (Campo. / Campo $y$ huerto, / por el camino del sueño $)^{22}$. Se suscita así una doble sorpresa: no sólo se vuelve al comienzo, sino que se vuelve a él "equivocadamente" (se violenta, de manera intencionada su literalidad). El cierre es, pues, doble: la vuelta en sí, la repetición de la estrofa de apertura, y su ruptura convencional.

6. El estribillo en Emilio Prados se configura normalmente como una suerte de repetición textual, la mayoría de las veces de un verso o una estrofa breve situada al comienzo del poema, sin que ésta sea, como era muy común con el villancico popular, una creación ajena al autor, preexistente (es decir, un cantar anónimo, nacido del pueblo, o de un vate de "antaño") ni dé lugar a la glosa, esto es, que represente un villancico glosado, como de dicha técnica numerosas muestras de la tradición lírica dan fe. La repetición cumple más bien una función estructurante, y en cierta medida rítmica, musical, cuando se practica con carácter cíclico o regular.

La poesía de estribillo de Prados también se aparta de la más clásica tendencia de las tradicionales formas poéticas del villancico de linaje aristocrático o villancico zejelesco y el propio zéjel, de estructura rítmica muy marcada por la disposición de la rima y la función textual de sus partes: cabeza -dístico monorrimo, generalmente-, mudanza, verso de vuelta...; se parece más, en cambio, a esa variante de la canción paralelística a que hemos aludido antes, mucho más libre en la configuración de las estrofas en cuanto no sigue necesariamente la estructura del pareado monorrimo y la vuelta no es siempre un único verso que haya de relacionarse rítmica y semánticamente con la cabeza, incluso que lo tenga que reproducir al pie de la letra: cada vuelta es, precisamente, una repetición del estribillo que, aunque no siempre, inicia normalmente el texto.

Las posiblidades formales de repetición del estribillo que se daban en las composiciones poéticas tradicionales (villancico, zéjel, cosaute...) también se observan en la obra de Prados; pero creemos que la repetición inexacta o con variaciones del enunciado iterativo o estribillo constituye otra característica representativa de su poesía estribillística, tal es el grado de recurrencia con que se produce. Considerada la repetición exacta como una norma o ley del verso, la voluntad de ruptura del patrón iterativo que representa el estribillo inicial consituye un recurso de estilo del escritor malagueño. En efecto, el grupo estrófico que funciona como estribillo no suele reproducirse en su forma pura en las sucesivas apariciones, no

22 Emilio Prados practica este último recurso de refuerzo del cierre textual, la adición de una nueva línea versal en la conclusión del poema, en otras creaciones líricas, como "Trinicad de la rosa (VII)": el texto se abre con el verso Yo estaba soñando: y se cierra con el pareado monorrimo de estructura paralelística Yo estaba soñando: / yo estaba pensando. 
se repite fielmente: es, por el contrario, frecuente o, incluso, habitual que nuestro poeta del 27 altere deliberadamente su estructura en un punto del desarrollo discursivo del poema.

\section{Referencias bibliográficas}

Alonso, D. (1949): “Cancioncillas 'de amigo' mozárabes. (Primavera temprana de la lírica europea)", $R F E, 33$, págs. 297-349 (reimp. en Alonso, D. (1961): Primavera temprana de la literatura española. Madrid, Guadarrama, págs. 17-79).

Asensio, E. (1953): "Los cantares paralelísticos castellanos. Tradición y originalidad", $R F E, 37$, págs. 130-167 (reimp. en Asensio, E. (1957): Poética y realidad en el cancionero peninsular de la Edad Media. Madrid, Gredos, págs. 69-133).

Baehr, R. (1962): Manual de versificación española. Madrid, Gredos, 1973.

Balbín Lucas, R. de (1962): Sistema de ritmica castellana. Madrid, Gredos, ${ }^{3} 1975$.

Cantera, F. (1949): "Versos españoles en las muwassahas hispano-hebreas", Sefarad, 9, págs. 197234.

Cantera, F. (1957): La canción mozárabe. Santander.

Coelho, A. (1912): "O paralelismo na poesia popular", Revista Lusitana, 15, págs. 21-36, 48-70.

Domínguez Caparrós, J. (1993): Métrica española. Madrid, Síntesis.

Domínguez Caparrós, J. (2002): Métrica de Cervantes. Alcalá de Henares, Centro de Estudios Cervantinos.

Frédéric, M. (1985): La répétition. Étude linguistique et rhétorique. Tubinga, Max Niemeyer Verlag. Frenk Alatorre, M. (1952): "Jaryas mozárabes y estribillos franceses", NRFH, 6, págs. 281-284.

Frenk Alatorre, M. (1953): "El nacimiento de la lírica española a la luz de los nuevos descubrimientos", Cuadernos Americanos, 67, págs. 159-174.

Frenk Alatorre, M. (1958): "Glosas de tipo popular en la antigua lírica", NRFH, 12, págs. 301-334.

Frenk Alatorre, M. (1961): "Refranes cantados y cantares proverbializados", $N R F H, 15$, págs. $155-$ 168 (reimp. en Frenk Alatorre, M. (1978): Estudios sobre lírica antigua. Madrid, Castalia, págs. 154-171).

Frenk Alatorre, M. (1966): Lírica hispánica de tipo popular. México, UNAM.

Frenk Alatorre, M. (ed.) (1983): Lírica española de tipo popular. Madrid, Cátedra.

Frenk Alatorre, M. (1997): "La relación compleja entre refranes y cantares antiguos". Paremia, 6, págs. 235-244.

García Gómez (1941): "Sobre el origen de la forma poética llamada glosa", Al-Andalus, 6, págs. 401-410.

García Gómez, E. (1949): "Más sobre las jarchas romances en muwassahas hebreas", Al-Andalus, 14 págs. 409-417.

García Gómez, E. (1950a): "Nuevas observaciones sobre las jarchas romances en muwassahas hebreas", Al-Andalus, 15, págs. 158-177.

García Gómez, E. (1950b): "El apasionante cancionerillo mozárabe", Clavileño, mayo-junio, págs. $17-21$.

García Gómez, E. (1956): "La lírica hispano-árabe y la aparición de la lírica románica", Al-Andalus, 21, págs. 303-338.

García Gómez, E. (1965): Las jarchas romances de la serie árabe en su marco. Madrid, Sociedad de Estudios y Publicaciones.

García-Page, M. (1988): "El lenguaje literal: su ruptura". En La lengua poética de Gloria Fuertes. Madrid, Universidad Complutense, cap. 2.

García-Page, M. (en prensa): "La repetición como sistema de cierre textual". En M. Casado et alii (2004): Actas del Congreso Internacional "Análisis del discurso: lengua, cultura, valores". Pamplona, Universidad de Navarra. 
Heger, K. (1960): Die bisher veröffentlichten Hargas und ihre Deutungen. Tubinga, anejo 101 de $Z R P h$.

Hrrnstein Smith, B. (1968): Poetic closure. A study of how poems end. Chicago-Londres, The University of Chicago Press.

Janner, H. (1943): "La glosa española. Estudio histórico de su métrica y de sus temas", RFE, 27, págs. 181-232.

Janner, H. (1946): La glosa en el Siglo de Oro. Una antología. Madrid.

Lausberg, H. (1960): Manual de retórica literaria. Madrid, Gredos, 3 vols.

Le Gentil, P. (1952): La poésie lyrique espagnole et portugaise è la fin du Moyen Âge. Deuxième partie: les formes. Rennes, Plihon Éditeur.

Le Gentil, P. (1954): Le virelai et le villancico. Le problème des origen arabes. París.

Mayoral Ramírez, J. A. (1994): Figuras retóricas. Madrid, Síntesis.

Menéndez Pidal, R. (1951): "Cantos románicos andalusíes, continuadores de una lírica latina vulgar", $B R A E, 31$, págs. 187-270.

Millás Vallicrosa, J. M. (1946): "Sobre los más antiguos versos en lengua castellana", Sefarad, 6, págs. 362-371.

Navarro Tomás, T. (1956): Métrica española. Reseña histórica y descriptiva. Barcelona, Labor.

Quilis Morales, A. (1984): Métrica española. Barcelona, Ariel, 1996.

Rodrigues Lapa, M. (1934): Liçôes de Literatura Portuguesa, Época Medieval. Coimbra.

Rodrigues Lapa, M. (1936): O villancico galego nos séculos XVII e XVIII. Lisboa.

Romeu Figueras, J. (1950): "El cosante en la lírica de los cancioneros musicales de los siglos XV y XVI", Anuario Musical, 5, págs. 15-61.

Romeu Figueras, J. (1954): "El cantar paralelístico en Cataluña. Sus relaciones con el de Galicia, Portugal y el de Castilla", Anuario Musical, 9, págs. 1-55.

Sánchez Romeralo, A. (1969): El villancico. (Estudios sobre la lírica popular en los siglos XV y XVI). Madrid, Gredos.

Saint Amour, M. P. (1940): A study of the villancico up to Lope de Vega: its evolution from profane to sacred themes, and specifically to the Christmas Carol. Washington.

Spitzer, L. (1952): "La lírica mozárabe y las teorías de Theodor Frings". En Spitzer, L. ( ${ }^{21974): ~}$ Lingüistica e Historia literaria. Madrid, Gredos, págs. 55-86.

Stern, S. M. (1948): "Les vers finaux en espagnol dans les muwassahs hispano-hébraïques. Une contribution à l'histoire du muwassah et à l'étude du vieux dialecte espagnol 'mozárabe"'. AlAndalus, 13, págs. 299-343.

Stern, S. M. (1951): "Studies on Ibn Quzman", Al-Andalus.

Stern, S. M. (1953): Les chansons mozarabes. (Les vers finaux (kharjas) en espagnol dans les 'muwashslahs' arabes et hébreux). Palermo, Universitá de Palermo.

Torner, E. M. (1966): Lírica hispánica. Relaciones entre lo popular y lo culto. Madrid, Castalia. 